\title{
Uso de mapas mentais nas representações perceptivas de alunos do ensino fundamental do município de Ilha Grande, Piauí, Brasil: o caso do jacaré (Caiman crocodilus)
}

\author{
Roberta Rocha da Silva-Leite ${ }^{1}$, \\ Zilca Campos ${ }^{2}$ \\ Paulo Augusto Zaitune Pamplin ${ }^{3}$
}

Resumo: O estudo da percepção pode contribuir de forma significativa para subsidiar propostas de conservação de espécies animais. Este estudo consistiu em verificar quais os tipos de relações perceptivas que os alunos do ensino fundamental do município de Ilha Grande (PI) possuem acerca do jacaré (Caiman crocodilus), visando contribuir para planos de educação ambiental. O método usado para a representação da percepção foi o emprego de mapas mentais. Os desenhos demonstraram a presença de elementos representativos da paisagem (landmarks) e a existência de ambiguidade em relação aos sentimentos dos alunos para com a figura do jacaré: sentimentos positivos (biofilia) e negativos (biofobia).

Palavras-chave: Biofilia. Conservação. Caiman.

1 Bióloga, mestre em Desenvolvimento e Meio Ambiente (PRODEMA/TROPEN). Contato: Universidade Federal do Piauí. Campus Universitário Ministro Petrônio Portella - Bairro Ininga - Teresina - PI. CEP: 64.049-550 roberta.ufpi@gmail.com

2 Engenheira florestal, pesquisadora da EMBRAPA Pantanal. Contato: zilca@cpap.embrapa.br

${ }^{3}$ Biólogo, professor adjunto da Universidade Federal de Alfenas - Campus Poços de Caldas. Contato: paulo.pamplin@unifal-mg.edu.br 


\begin{abstract}
The study of perception can contribute significantly to support proposals for animal species conservation. This study sought to find out what kinds of perceptive relationship the middle school student population from the city of Ilha Grande (PI) has about the caiman, aiming to provide background information to environmental education plans. Mental maps were used to represent each perception, and the drawings showed the presence of representative elements of the landscape (landmarks) and the existence of ambiguity in relation to the students' feelings about the figure of caiman: positive feelings (biophilia) and negative feelings (biophobia).
\end{abstract}

Keywords: Biophilia. Conservation. Caiman.

\title{
Introdução
}

A palavra "percepção" vem do latim perceptio, que se refere ao ato de perceber, ação de formar mentalmente representações sobre objetos externos a partir dos dados sensoriais (NEIMAN, 2007). Assim, a percepção da paisagem é derivada de fatores educacionais e culturais, além de fatores emotivos, afetivos e sensitivos, sendo estes últimos oriundos das relações que o observador mantém com o ambiente à sua volta. Ainda de acordo com o autor, a percepção, bem como a educação, deve ser utilizada para possibilitar a expansão de uma consciência conservacionista através do envolvimento afetivo das pessoas com a natureza e a cultura local. Machado (1999) ressalta a percepção ambiental como fundamental para se entender a preferência, o gosto e as ligações cognitivas e afetivas dos seres humanos para com o meio ambiente, uma vez que se constituem na grande força que modela a superfície terrestre através de escolhas, ações e atitudes ambientais.

O modo como os seres humanos percebem, identificam, categorizam e classificam o mundo natural influencia o modo como eles pensam, atuam e expressam emoções com relação aos animais (SILVA; COSTA NETO, 2004). Mansano et al. (2005) destacam ainda que a percepção ambiental de uma criança não é a mesma de um adulto, porque cada um possui os elementos para perceber o mundo de acordo com sua experiência. 
Nesse contexto, procurou-se investigar a percepção de alunos do ensino fundamental com relação à representatividade da figura do jacaré (Caiman crocodilus LINNAEUS, 1758) no município de Ilha Grande, Piauí. Esse animal está distribuído no Brasil desde a região amazônica (RUEDA-ALMONACID et al., 2007) até o Planalto do Ibiapaba, Ceará (BORGES-NOJOSA; CASCON, 2005; LOEBMANN; HADDAD, 2010), habitando áreas pantanosas (alagadiços), florestas, rios e igarapés, sendo comum sua ocorrência no município estudado, porém, carece de estudos locais.

Essa espécie é considerada de baixo risco de extinção pela União Internacional para a Conservação da Natureza (INTERNATIONAL UNION FOR CONSERVATION OF NATURE ,2010), estando na categoria Least Concern (LC) e na lista da Convenção sobre o Comércio Internacional de Espécies da Flora e Fauna Selvagens em Perigo de Extinção - CITES (Apêndice II) (UNITED NATIONS ENVIRONMENT PROGRAMME WORLD CONSERVATION MONITORING CENTRE, 2010). Villaça (2004) destaca que a IUCN indica projetos com moderada prioridade para essa espécie, entre eles a implementação de iniciativas de manejo sustentável, a diminuição do comércio ilegal de peles e estudos taxonômicos aprofundados para melhor definição das espécies e/ou subespécies.

A figura do jacaré comumente está associada a sentimentos de medo e pânico na humanidade. Esses sentimentos são passados de pais para filhos, o que termina por ocasionar uma "repulsa" a esses animais, influenciando negativamente procedimentos de conservação. Salera Júnior (2008) comenta a importância da desmistificação de imagens errôneas e negativas sobre a figura representativa dos crocodilos e jacarés em todo o mundo. $\mathrm{O}$ autor ressalta filmes e programas de TV em que a presença de jacarés é associada ao medo e ao pavor (ex.: Crocodilo Dundee I e II, Pânico no Lago, As Aventuras de Peter Pan, O Sítio do Pica-Pau Amarelo etc.).

A ausência de estudos com a espécie na região requer atenção especial, visto que o município de Ilha Grande está situado numa Área de Proteção Ambiental, não possuindo plano de manejo até o presente momento, o que implica vulnerabilidade desses animais, principalmen- 
te por sua representatividade (temor e alvo para caça) e destruição de habitats (assoreamento de rios e degradação da vegetação ripária).

Destarte, a afetividade é o impulso que direciona a percepção, ou seja, a emoção da vinculação das pessoas ao seu ambiente, ao meio que as cerca, no caso deste estudo, a figura do jacaré. O indivíduo processa mentalmente as informações que o meio e a herança cultural lhe oferecem e sua conduta é construída mediante o equilíbrio entre os fatores internos e externos.

No presente trabalho, a percepção sobre o jacaré foi trabalhada através da representação denominada mapas mentais. Essa representação atua como um prolongamento da percepção, pois introduz um sistema de significação representativo, envolvendo a diferenciação entre os significantes, que podem ser as formas de linguagem ou imagens, gestos, desenhos, e os significados, que compreendem os espaços (DEL RIO; OLIVEIRA, 1997). Cada imagem e ideia sobre o mundo é composta então de experiência pessoal, aprendizado, imaginação e memória (MACHADO, 1999). De acordo com Barros (1997 apud MAROTI, 2002), o uso de mapas mentais (ou cognitivos) tem sido considerado como metodologia adequada às pesquisas socioambientais em comunidades de indivíduos com pouca ou nenhuma escolaridade, especialmente pela riqueza de informações objetivas e simbólicas que pode proporcionar. Maroti (2002) complementa afirmando que esses mapas são utilizados para a representação gráfica dos elementos físicos, biológicos e antrópicos presentes em uma determinada área da paisagem com base na experiência do indivíduo.

As imagens (mapas mentais) contribuem de forma significativa para a representação de pontos de identificação ambiental (landmarks). De acordo com Allen et al. (1979), o termo "landmark" é considerado como um ponto de identificação ambiental, opcionalmente definido, com implicações perceptuais cognitivas e ambientais. Niemeyer (1994) considera o referido termo como um ponto de referência com base no qual o espaço definido pelo entrevistado está, direta ou indiretamente, associado com a relação afetiva, em geral cultural, e com as variáveis mais restritivas, como profissão, especialização, experiência, idade e familiaridade, as quais atuam através da seleção mental das informações 
do ambiente. Maroti (2002) sintetiza essas ideias enquadrando a análise de mapas mentais em momentos distintos de um processo educativo induzido, com base na identificação desses elementos simbólicos (landmarks) formados nas diferentes fases de um processo.

Este estudo consistiu em verificar quais tipos de relações perceptivas a população estudantil pertencente ao $6^{\circ}$ e $9^{\circ}$ anos do ensino fundamental do município de Ilha Grande, PI, possui com relação ao jacaré, Caiman crocodilus, visando contribuir para futuros planos de educação ambiental voltados à temática da conservação do animal em questão.

\section{Área de estudo}

O município de Ilha Grande (02051'37’'S e 41\%49'15'W) está localizado na Área de Proteção Ambiental Delta do Parnaíba, estado do Piauí, na microrregião do litoral piauiense, compreendendo uma área de $134,0 \mathrm{~km}^{2}$ (INSTITUTO BRASILEIRO DE GEOGRAFIA E ESTATÍSTICA, 2007; ILHA GRANDE, 2008). O município tem como limites o Oceano Atlântico a norte e a leste; o município de Parnaíba a sul e a leste e o estado do Maranhão, separado pelo Rio Parnaíba, a oeste. Distante cerca de $326 \mathrm{~km}$ da capital Teresina, Ilha Grande está inserida na bacia hidrográfica difusa do Baixo Parnaíba. O meio biológico florístico compreende quatro formações vegetacionais: Manguezal, Carnaubal, Fruticeto de Restinga e Campo Herbáceo. A fauna é composta por várias espécies de mamíferos, aves, peixes, anfíbios e répteis, entre estes últimos o jacaré (Caiman crocodilus) (FUNDAÇÃO CENTRO DE PESQUISAS ECONÔMICAS E SOCIAIS DO PIAUÍ , 1996; ILHA GRANDE, 2008).

De acordo com Lustosa (2005), as atividades mais expressivas na região são a pesca, carcinicultura, agricultura de subsistência, extrativismo vegetal, pecuária extensiva, produção artesanal e turismo, esta última se configurando como uma das maiores potencialidades locais, graças à singularidade das paisagens, à diversificação da fauna e ao clima propício durante todo o ano, necessitando, segundo a autora, de planejamento e gestão adequados.

Com relação à educação, os discentes do município de Ilha Grande são atendidos com os diferentes níveis de ensino: pré-escolar, 
fundamental e médio. Os ensinos pré-escolar e fundamental são oferecidos tanto no meio urbano quanto no rural; o ensino médio, apenas na zona urbana (ILHA GRANDE, 2008). Não há nenhuma Instituição de Ensino Superior no município até o momento.

\section{Caracterização das escolas estudadas}

Foi realizado um censo em todas as escolas do município de Ilha Grande que possuíam $6^{\circ}$ e $9^{\circ}$ anos do ensino fundamental, totalizando cinco escolas (uma estadual e quatro municipais). A primeira escola visitada foi a escola estadual Unidade Escolar Marocas Lima (UEML), localizada no centro do município. Essa região pode ser caracterizada pela maior concentração de moradias e comércios, possuindo um pequeno porto situado às margens de um igarapé utilizado por catadores de caranguejo e pescadores locais. A segunda escola visitada foi a Escola Municipal Zila Almeida (EMZA), localizada também na região central e tendo as mesmas características de entorno observadas na escola UEML. A terceira foi a Escola Municipal Dom Paulo Hipólito de Souza Libori (EMDPHSL), localizada no bairro Tatus, meio urbano, nas proximidades do porto de maior importância para o município, o Porto dos Tatus, que também fica próximo às dunas e lagoas pluviais da região. A quarta foi a Escola Municipal Santa Joana D'Arc (EMSJD), localizada no bairro Barro Vermelho, zona rural, cuja região do entorno é caracterizada pela presença de carnaubais e algumas lagoas temporárias. A última foi a Unidade Escolar Municipal Maria de Lourdes Pinheiro Machado (EMMLPM), situada no bairro Labino, zona rural, às margens da Rodovia Estadual PI-210, a qual divide os municípios de Ilha Grande e Parnaíba. As características dessa área são semelhantes às da EMSJD, com a presença de carnaubais e lagoas temporárias.

\section{Instrumento de avaliação e procedimentos}

A coleta das informações de campo nas escolas com os alunos ocorreu entre os meses de fevereiro e abril de 2009. Para avaliar a percepção, foi entregue a cada aluno uma folha de papel tamanho A4 com o seguinte comando: "Faça um desenho sobre o jacaré no Delta 
do Parnaíba". Os desenhos foram designados aqui como mapa mental ou cognitivo.

A confecção de desenhos permitiu, de forma livre, a expressão da ideia que o aluno tem do jacaré no Delta do Parnaíba e a inserção ou não de elementos da natureza ou pontos de identificação ambiental (landmarks) associados à figura do jacaré.

\section{Amostragem}

A escolha do $6^{\circ}$ e $9^{\circ}$ anos escolares se deveu ao fato de serem considerados períodos de transição na vida do estudante: transição infância-adolescência $\left(6^{\circ}\right.$ ano) e amadurecimento da adolescência $\left(9^{\circ}\right.$ ano). Acredita-se que essas etapas sejam fases diferentes de maturidade dos alunos, sendo o $6^{\circ}$ ano uma etapa na qual os alunos já dominam razoavelmente a escrita, mas ainda estão na infância, trazendo consigo um conhecimento mais enraizado familiarmente (BEZERRA; FELICIANO; ALVES, 2008), e o $9^{\circ}$ ano, uma etapa mais avançada do conhecimento escolar, na qual o conhecimento de raízes familiares (tradicional) tende a receber com maior frequência influências do meio.

Para a aquisição dos dados de campo, participaram 186 alunos do $6^{\circ}$ ano do ensino fundamental, sendo 29 da UEML, 82 da EMZA, 29 da EMDPHSL, 24 da EMSJD e 22 da EMMLPM; e 86 alunos do $9^{\circ}$ ano do ensino fundamental, distribuídos da seguinte forma: 29 da UEML, 31 da EMZA, 11 da EMDPHSL, 8 da EMSJD e 7 da EMMLPM, perfazendo um total de 272 alunos amostrados, ou seja, $87,2 \%$ do total de alunos regularmente matriculados nessas séries escolares (ano-base 2009) do município em estudo.

Com relação à faixa etária dos alunos amostrados, para o $6^{\circ}$ ano obtiveram-se alunos com idades entre 8 e 17 anos, a maioria (26,9\%) possuindo 11 anos de idade; para alunos do $9^{\circ}$ ano a faixa etária variou entre 12 e 20, tendo a maior parte dos alunos (34,9\%) 15 anos de idade.

\section{Análise dos dados}

Para a análise dos desenhos foi feita uma identificação dos temas, seguida da sua separação e agrupamento por categoria. Em 
função da grande diversidade de ilustrações, foi realizada uma nova triagem por subtemas, e os dados foram agrupados em categorias de acordo com cada subtema, adaptando-se a metodologia adotada por Melos (2005). A análise dos desenhos contou ainda com a metodologia de interpretação quanto à forma de representação dos elementos na imagem (KOZEL, 2001). Uma análise descritiva através de elementos expressivos da paisagem, os chamados pontos de identificação ambiental (landmarks), adaptada do modelo de Maroti (2002), também foi utilizada.

Após a etapa acima, os desenhos foram agrupados por série escolar, unidade escolar e faixa etária, esta última sendo dividida em três grupos: G1, compreendendo alunos entre 8 e 11 anos de idade; G2, entre 12 e 15; G3, entre 16 e 20, independentemente da série escolar.

\section{RESUltados E Discussão}

\section{Representatividade dos desenhos em categorias}

Numa primeira triagem, as ilustrações foram agrupadas em quatro categorias. A primeira, a categoria de respostas gerais (primeira triagem), separou os desenhos em outras categorias. A realização desses agrupamentos (triagens) torna as relações de percepção alunojacaré mais explícitas e analisáveis (Tabela 1), já que os desenhos tendem a deixar uma interpretação bem vasta para cada pessoa que os vê. Foram escolhidos os desenhos mais representativos por categoria para ilustrar este trabalho.

Nesse contexto, as quatro categorias obtidas para a primeira triagem foram: (1) "Jacaré apenas", em que os alunos desenharam apenas o animal sem outros elementos, ou seja, os alunos não contextualizaram o animal com seu babitat ou qualquer landmark; (2) "Jacaré + natureza", em que os alunos desenharam o animal com alguns elementos da natureza ao redor, ou mesmo em comportamentos reprodutivo e/ou alimentar, o que significa, de certa forma, que esses alunos conseguem contextualizar o animal no seu habitat, mesmo que este esteja representado, por exemplo, por alguns 
riscos no papel representando a água; (3) "Jacaré + homem", em que os alunos desenharam o jacaré e a figura do ser humano, sem o contexto da natureza; (4) "Jacaré + natureza + homem", em que aparecem desenhos mais completos, ou seja, os alunos contextualizam a figura do jacaré e a do homem, ambos inseridos no "cenário natureza". Dos 272 alunos pesquisados, apenas 22 (8,1\%) não desenharam nada.

Tabela 1: Categorias de respostas (desenhos) obtidas de acordo com Série Escolar, Unidade Escolar, Faixa Etária e para Todos os Alunos (geral). Faixa etária: $\mathrm{G} 1=8-11, \mathrm{G} 2=12-15 ; \mathrm{G} 3=16-20$.

\begin{tabular}{|c|c|c|c|c|c|c|c|c|c|c|c|}
\hline \multirow{2}{*}{$\begin{array}{c}\text { Respostas } \\
\text { Obtidas } \\
\text { Categorizadas }\end{array}$} & \multicolumn{2}{|c|}{$\begin{array}{c}\text { Série } \\
\text { Escolar } \\
(\%)\end{array}$} & \multicolumn{5}{|c|}{ Unidade Escolar $(\%)$} & \multicolumn{3}{|c|}{ Faixa Etária (\%) } & \multirow{2}{*}{$\begin{array}{c}\text { Todos os } \\
\text { alunos } \\
(\%)\end{array}$} \\
\hline & $6^{\circ}$ & $9^{0}$ & UEML & EMZA & EMDPHSL & EMSJD & EMMLPM & G.1 & G.2 & G.3 & \\
\hline Jacaré apenas & 39,8 & 40,7 & 29,3 & 46,0 & 15,0 & 46,8 & 65,5 & 35,2 & 42,1 & 40,0 & 37,2 \\
\hline $\begin{array}{ll}\text { Jacaré } & + \\
\text { natureza } & \\
\end{array}$ & 45,2 & 50,0 & 48,3 & 40,7 & 75,0 & 46,9 & 27,6 & 49,3 & 45,6 & 46,7 & 46,7 \\
\hline $\begin{array}{l}\text { Jacaré } \\
\text { homem }\end{array}$ & 1,6 & 0 & 0 & 0.9 & 2,5 & 0 & 3,4 & 2,8 & 0,6 & 0 & 1,1 \\
\hline $\begin{array}{ll}\text { Jacaré } & + \\
\text { natureza } & + \\
\text { homem } & \\
\end{array}$ & 6,4 & 8,1 & 6,9 & 8,8 & 10,0 & 3,1 & 3,4 & 8,4 & 6,4 & 6,7 & 6,9 \\
\hline $\begin{array}{l}\text { Não } \\
\text { desenharam }\end{array}$ & 6,9 & 1,2 & 15,5 & 3,5 & 0 & 3,1 & 0 & 4,2 & 5,3 & 6,7 & 8,1 \\
\hline
\end{tabular}

Os maiores percentuais obtidos foram relativos aos desenhos da categoria "Jacaré + natureza" ( $n=127$ ou 46,7\%). Isso pode ser explicado, pois no momento da amostragem o pesquisador sugeriu que se desenhasse o jacaré no delta, ou seja, supondo que o aluno desenhasse a figura do jacaré inserido em alguma imagem que representasse para ele a região onde mora (contextualização). A segunda resposta com percentual mais alto foi "Jacaré apenas" ( $\mathrm{n}=101$ ou $37,2 \%$ ) e provavelmente está ligada à maior facilidade e praticidade em desenhar apenas o animal sozinho, sem detalhes de contextualização. Por fim, as outras duas categorias, "Jacaré + natureza 
+ homem" e "Jacaré + homem", foram as que tiveram menor representatividade, com $6,9 \%(n=19)$ e $1,1 \%(n=3)$, respectivamente.

$\mathrm{Na}$ figura 1 são apresentados alguns dos desenhos inseridos na categoria "jacaré + natureza". Essa categoria foi subdividida, gerando quatro respostas diferentes para a interpretação dos desenhos. São elas: "Jacaré em comportamento alimentar", que se refere a algum animal desenhado sendo predado pelo jacaré; "Jacaré em comportamento reprodutivo", relacionada à presença de alguma figura que representa o comportamento reprodutivo do mesmo (p. ex., ninhos com ovos); "Jacaré em seu habitat", relacionada à presença de algum elemento que representa o babitat do animal em estudo (p. ex., água, igarapés e manguezais) e "Jacaré em comportamento alimentar e reprodutivo", uma junção dos dois primeiros tipos de respostas. Essas categorias de respostas são bastante importantes, levando-se em consideração que detalhes como animais sendo predados e ovos ou ninhos com ovos são considerados elementos cruciais para a sobrevivência da espécie em estudo.

Dessas quatro subcategorias, a que obteve maior percentual foi "Jacaré em seu habitat", com 80,3\% (n=102) do total para a categoria. Como essa subcategoria de desenho aparentemente é a mais simples entre as outras três estabelecidas, porque não envolve pormenores, como desenhos comportamentais (Figura 1), justifica-se seu maior percentual.

É importante notar que os ninhos ilustrados apresentam grandes quantidades de ovos, corroborando os dados da literatura, que citam que o número de ovos de Caiman crocodilus por postura varia de 14 a 38-40 (AZEVEDO, 2003; CAMPOS et al., 2008), ressaltando assim a fiel relação da representação perceptiva das crianças com a realidade (Figuras 1B, 1D e 1E).

$\mathrm{Na}$ Figura 1A, além do comportamento alimentar, pode-se observar um indicativo de poluição na presença de uma garrafa no habitat ocupado pelo jacaré. Cabe chamar a atenção aqui para a conservação, pois, segundo Rodrigues (2005), a destruição de habitats é a ameaça principal aos répteis. Já na figura 1D, pode-se constatar uma maior complexidade de informações, desde a inserção do jacaré em seu babitat, representado pela água e árvores, passando pelo 
comportamento alimentar, evidenciado no ato de se alimentar de um peixe e de uma serpente, sendo o primeiro considerado o principal item na dieta dos jacarés (AZEVEDO, 2003), até o comportamento reprodutivo, representado pela postura de ovos (ninho). Vale salientar que esse desenho foi o único dessa categoria, tendo sido feito por um aluno do $6^{\circ}$ ano da EMDPHSL, a escola com localização mais próxima dos corpos d'água, tanto de lagoas como de rios e igarapés.
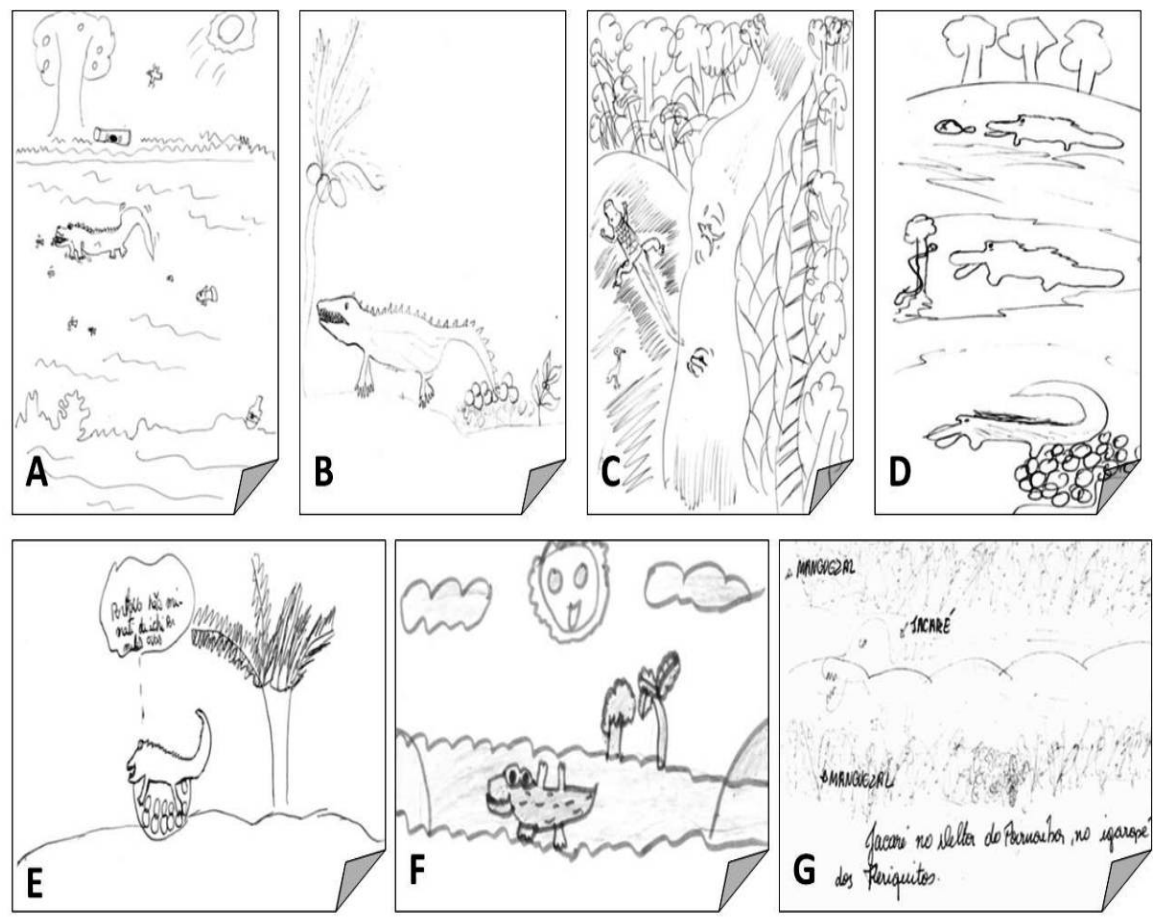

Figura 1: Exemplos de desenhos da categoria "Jacaré + natureza". A - $6^{\circ}$ ano EMMLPM (11 anos) (Jacaré em comportamento alimentar); B $-6^{\circ}$ ano EMZA (13 anos) (Jacaré em comportamento reprodutivo); $\mathrm{C}-9^{\circ}$ ano EMDPHSL (16 anos) (Jacaré em seu habitat); D $-6^{\circ}$ ano EMDPHSL (15 anos) (Jacaré em comportamento alimentar e reprodutivo); $\mathrm{E}-6^{\circ}$ ano EMDPHSL (12 anos) (Jacaré em comportamento reprodutivo); F - $6^{\circ}$ ano EMZA (11 anos) (Jacaré em seu habitat); $\mathrm{G}-9^{\circ}$ ano UEML (13 anos) (Jacaré em seu habitat).

As Figuras 1C e $1 \mathrm{G}$ merecem destaque pela representatividade dos manguezais, ilustrados por árvores típicas desse ecossistema, bem como pela grafia "manguezal" (Figura 1G), sendo um dos ecossistemas mais expressivos da região do delta habitado pelo jacaré. 
No item "Jacaré + homem" foram categorizadas duas possíveis respostas para a interpretação dos desenhos: "Jacaré e homem sem expressão", em que apenas foram desenhados o homem e o jacaré, sem nenhum tipo de interação (p. ex., Figura 2A), e "Comportamento agressivo do homem para com o jacaré”, com desenho que configura algum tipo de comportamento agressivo do ser humano para com o animal. $\mathrm{Na}$ Figura 2B, pode-se notar um jacaré com marcas de feridas pelo corpo e a presença de um homem (canto superior esquerdo) com uma suposta "arma" na mão, merecendo destaque a figura humana ilustrada em tamanho bem menor que o jacaré, do que se infere que a percepção do aluno demonstra a diferença de poder entre os dois símbolos, ou seja, um (jacaré) grande e supostamente "perigoso" e o outro (homem) pequeno, mas dominante na situação, tendo o seu poder demonstrado através da arma e da "morte" do animal para sua "defesa".

Já na Figura 2C, a agressividade do homem para com o jacaré é representada por uma lança do homem em direção ao animal. Esse objeto pode denotar um comportamento de defesa, porém, nesse caso, o fato de o animal estar virado de costas para o homem pode indicar um comportamento de caça, levando-se em conta informações locais sobre o uso de uma espécie de lança para o abatimento de alguns animais para o consumo.

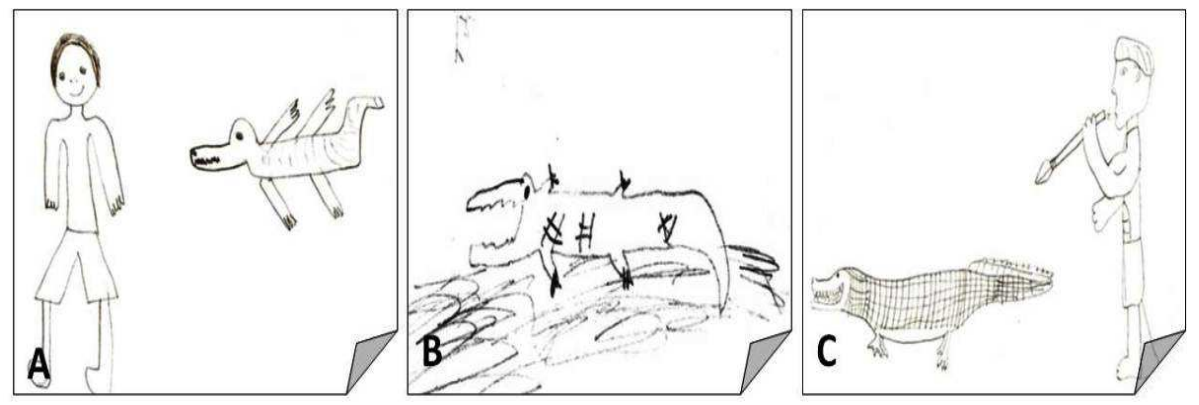

Figura 2: Exemplos de desenhos da categoria "Jacaré + homem". A - $6^{\circ}$ ano EMZA (11 anos) (Jacaré e homem sem expressão); B $-6^{\circ}$ ano EMDPHSL (11 anos) (Comportamento agressivo do homem para com o jacaré); $\mathrm{C}-6^{\circ}$ ano EMMLPM (15 anos) (Comportamento agressivo do homem para com o jacaré). 
No item "Jacaré + natureza + homem" foram categorizadas seis respostas diferentes, quais sejam: "Comportamento agressivo do homem para com o jacaré", que, da mesma forma que o item anterior, designa algum tipo de comportamento de agressividade do homem para com o animal; "Comportamento agressivo do jacaré para com o homem", sendo o inverso da resposta anterior; "Disputa por alimento"; "Água, jacaré fora ou dentro da água com barcos e/ou casas e/ou pessoas e/ou ponte", que demonstra uma boa inserção da figura do animal no seu habitat com elementos antrópicos; "Jacaré em comportamento alimentar no rio e homem observando-o do barco", parecida com a interpretação para a resposta anterior, porém, necessariamente com a presença humana; "Convivência harmônica homem-jacaré", significando uma relação "sem conflitos" entre o jacaré e o homem.

A categoria que obteve maior percentual foi “Água, jacaré fora ou dentro da água com barcos e/ou casas e/ou pessoas e/ou ponte", com 57,9\% ( $=11)$, destacando aqui a importância da relação de antropização com a natureza, neste caso o jacaré; a segunda maior porcentagem foi alcançada pela categoria "Convivência harmônica homem e jacaré", o que deve ser levado em conta no sentido de cooperação e divisão de habitat (animal e homem).

$\mathrm{Na}$ Figura 3A, a demonstração de agressividade do homem para com o jacaré pode ter a mesma denotação da Figura 3C, possivelmente um exemplo de caça fazendo-se o uso do instrumento lança. Todavia, na Figura 3B, o comportamento de agressividade é explícito, visto que a figura humana aponta uma arma em direção ao jacaré, em um cenário típico do Manguezal (habitat do animal em estudo), caracterizado por fileira mais ou menos homogênea de árvores ao fundo. Já na Figura 4C, há uma relação de agressividade do jacaré para com o homem, representada pelo animal em tamanho muito superior ao do homem, o que sugere a ideia de que este é uma figura frágil e que corre perigo na presença daquele a ponto de ser morto.

A Figura 3D caracteriza bem uma referência antrópica da região de estudo: trata-se da imagem de um jacaré na água embaixo de uma ponte, designada pelo aluno no desenho como a ponte do "Rio Parnaíba" (na verdade um braço do Rio Parnaíba, denominado 
Igaraçu), que liga o centro da cidade de Parnaíba à unidade geográfica Ilha Grande de Santa Isabel, na qual se insere o município-alvo deste estudo. No referido rio, constata-se a presença de jacarés (Caiman crocodilus).

$\mathrm{Na}$ Figura 3E, pode-se observar o jacaré em comportamento alimentar associado à fala "eu sou mau, muito mau", a qual designa uma personalidade perversa do animal. Ademais, o fato de o jacaré estar predando um peixe pode estar associado a uma demonstração de poder, já que o homem que o observa do barco também faz uso do mesmo recurso alimentar. A Figura 3F contém um ser humano e um jacaré no mesmo ambiente sem aparente interação, o que denota uma relação positiva entre ambos, ou seja, uma suposta convivência harmônica, uma partilha de babitat. $\mathrm{Na}$ Figura $3 \mathrm{G}$ pode-se notar a presença de uma embarcação típica da região deltaica (canoa a vela), com dois homens observando um jacaré que se encontra na água. Nota-se também que ao redor do jacaré aparece uma árvore de mangue (ver raízes aéreas). Essa cena (avistagem de jacaré), segundo informações dos alunos, é bem comum na região.

A Figura $3 \mathrm{H}$ é um bom exemplo de convivência harmônica homem-jacaré. Além disso, as escritas que acompanham esse desenho evidenciam a importância da conservação desse animal: "olha um jacaré tão bonitinho mas muita gente quer matar" e "vamos parar de maltratar ao jacarés, eles fazem parte da natureza. É um animal que Deus colocou no mundo".

Somente a categoria "Jacaré apenas" não foi desmembrada em outras, pois para os alunos que desenharam apenas o jacaré não foi necessária a interpretação mais detalhada desses desenhos porque não houve distinção de ideias entre eles (Figura 4). 


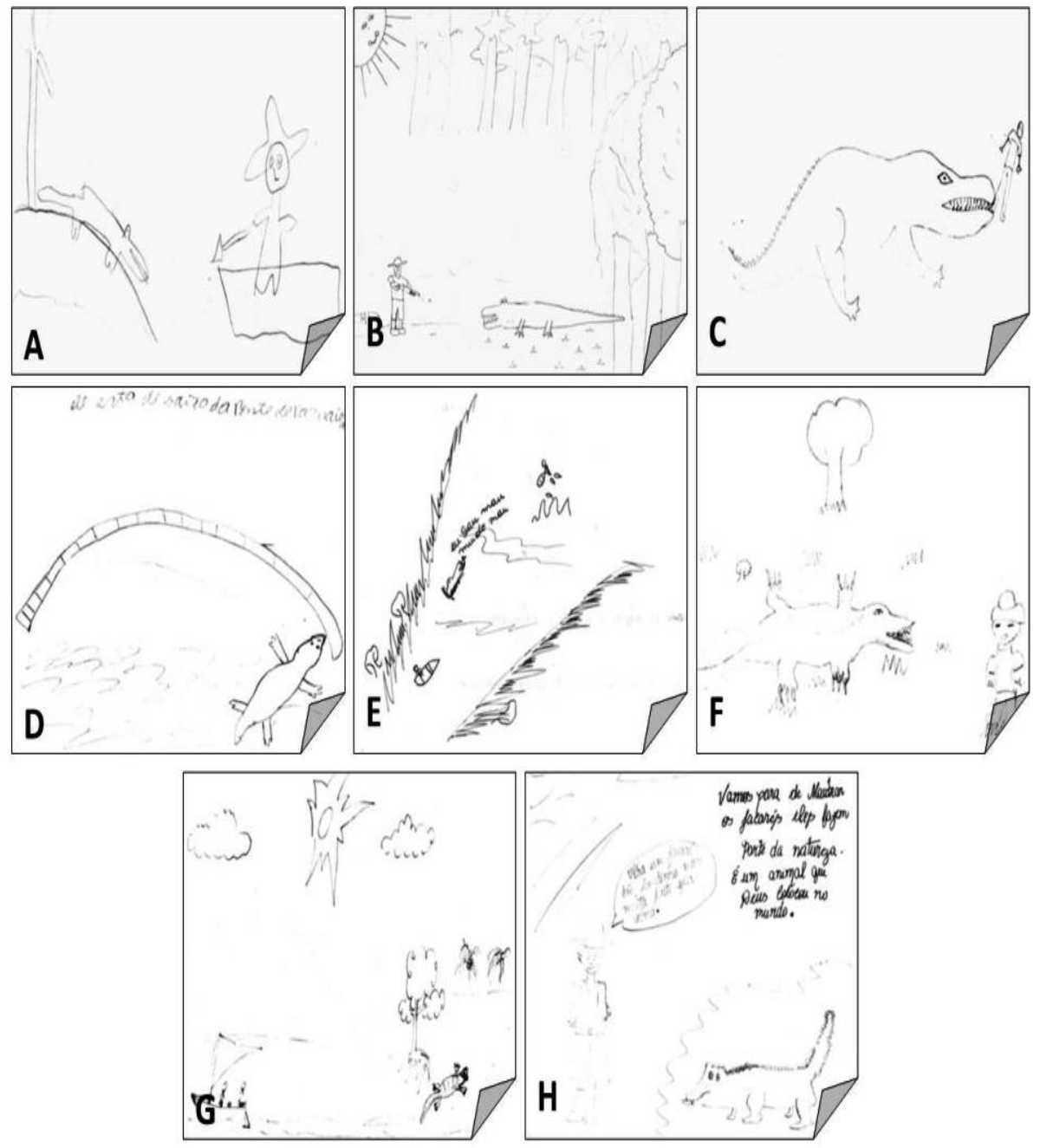

Figura 3: Exemplos de desenhos da categoria "Jacaré + natureza + homem". A $-6^{\circ}$ ano EMZA (11 anos) (Comportamento agressivo do homem para com o jacaré); $\mathrm{B}-9^{\circ}$ ano UEML (14 anos) (Comportamento agressivo do homem para com o jacaré); $\mathrm{C}-9^{\circ}$ ano EMZA (13 anos) (Comportamento agressivo do jacaré para com o homem); D $-6^{\circ}$ ano EMZA (10 anos) (Água, jacaré dentro da água e ponte); E - $6^{\circ}$ ano EMZA (14 anos) (Jacaré em comportamento alimentar no rio e homem observando-o do barco); $\mathrm{F}-6^{\circ}$ ano EMMLPM (11 anos) (Convivência harmônica homem-jacaré); $G-9^{\circ}$ ano EMDPHSL (17 anos) (Água, jacaré dentro da água com barco e pessoas); $\mathrm{H}-6^{\circ}$ ano UEML (14 anos) (Convivência harmônica homem-jacaré). 


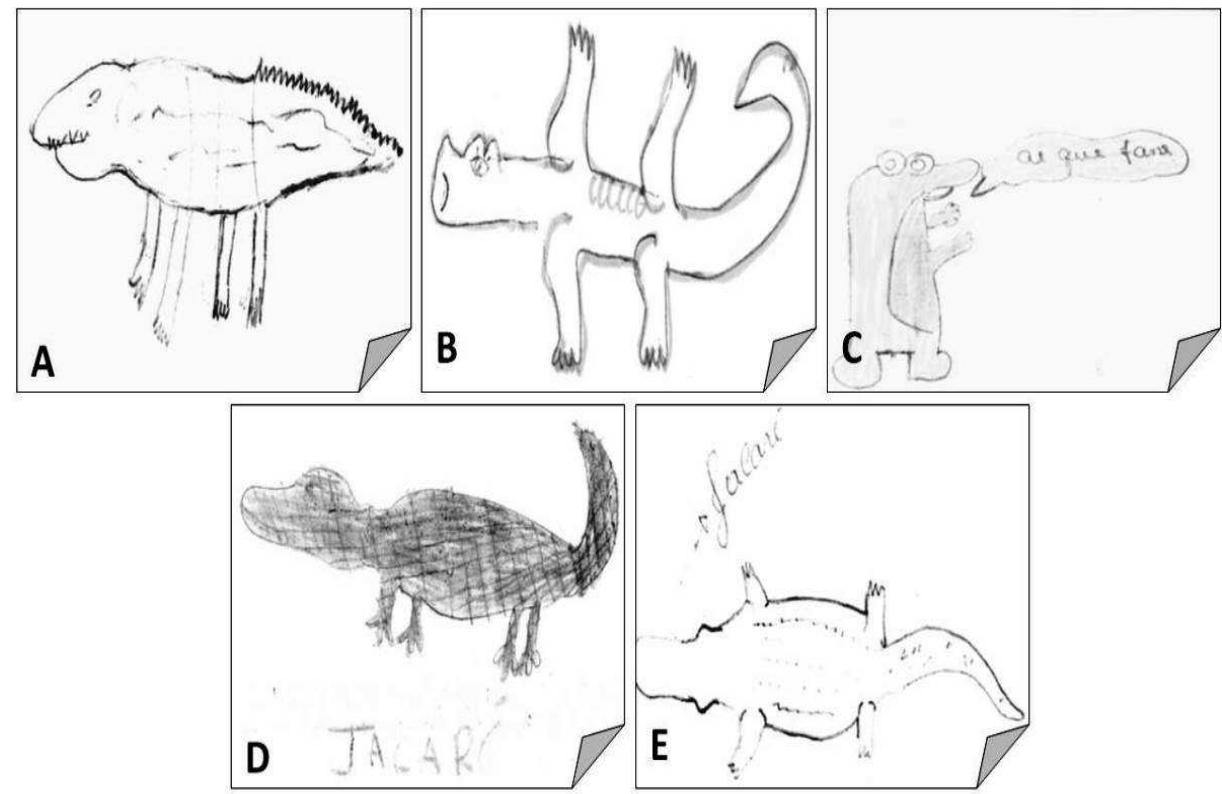

Figura 4: Exemplos de desenhos da categoria "Jacaré apenas". A - $6^{\circ}$ ano EMSJD (12 anos); $\mathrm{B}-6^{\circ}$ ano EMZA (10 anos); $\mathrm{C}-6^{\circ}$ ano EMDPHSL (10 anos); D $-9^{\circ}$ ano EMZA (15 anos); $\mathrm{E}-6^{\circ}$ ano EMMLPM (10 anos).

\section{Abordagem perceptiva de acordo com a série escolar, escola e faixa etária}

Como mencionado, a maior parte dos desenhos se enquadra na categoria "Jacaré + natureza" (46,7\%). Os alunos do $6^{\circ}$ ano, assim como os do $9^{\circ}$ ano, tiveram seus desenhos representados em maior porcentagem $(45,2 \%$ e $50,0 \%$, respectivamente) nessa categoria. Representar o jacaré inserido no contexto natureza não parece estar diretamente ligado ao aprendizado escolar propriamente dito, ou seja, a associação que o aluno pode fazer da percepção com o conteúdo disciplinar de uma ou outra série escolar, mas sim ao senso comum.

Pode-se seguir o mesmo raciocínio para as faixas etárias que também não apresentaram diferença (G1=49,3\%, G2 $=45,6 \%$, $\mathrm{G} 3=46,7 \%)$ quanto à categoria de desenhos mais representada (jacaré+natureza). Cabe aqui inferir a questão do conhecimento adquirido empiricamente, aquele repassado de geração para geração, que nesta situação não fez diferença do tempo de experiência (idade) 
do indivíduo. A percepção nesse caso poderia estar também relacionada à capacidade de entender (perceber) o meio (jacaré) de acordo com a maturidade (e não com a idade) de cada um, adicionando-se o componente "ambientes (locais) frequentados" em comum (jacarés e alunos).

Por sua vez, a maioria das escolas (UEML, EMDPHSL, EMSJD) também teve o maior percentual (48,3\%, 75,0\% e 46,9\%, respectivamente) de desenhos inseridos na categoria "Jacaré + natureza". As escolas EMZA e EMMLPM, no entanto, tiveram a maior parte $(46,0 \%$ e $65,5 \%$, respectivamente) de seus desenhos representados na categoria "Jacaré apenas". Uma interpretação possível para esse resultado é o fator localização geográfica da escola, uma vez que escolas situadas mais próximo a habitats ocupados pelo jacaré na região, como é o caso da EMDPHSL e da EMSJD, tendem a ter alunos que representam o animal mais fielmente inserido nesses habitats (natureza), pois o fato de o aluno freqüentar a escola faz com que sua percepção esteja voltada para a realidade que o cerca (dia a dia). Como não há conhecimento da realidade particular de cada aluno, outras interpretações são possíveis para o resultado encontrado.

\section{Biofilia e biofobia no contexto alunos e jacarés}

$\mathrm{Na}$ interpretação de alguns dos desenhos destacados neste trabalho (Figuras 2A, 3G, 3F e 3H), pode-se atribuir sentimentos de biofilia na relação aluno-jacaré. Uma definição para o termo biofilia é bem clara nas palavras de Wilson (1993 apud SILVA; COSTA NETO, 2004), que a descreveu como "uma necessidade humana inata (portanto, genética) para contato com uma diversidade de formas de vida". Filgueiras (2007) também trabalha bem a definição desse termo colocando a expressão como um sentimento de amor à vida e, por extensão, a tudo o que é vivo, a todas as manifestações da vida. Ressalta ainda o apreço e o respeito a todos os organismos vivos do planeta, sejam eles diretamente ligados à vida humana ou não.

O exemplo mais explícito de biofilia homem-jacaré nos desenhos expostos é a Figura $3 \mathrm{H}$, conforme explicado pela interpretação do desenho. A presença desse sentimento revela que os alunos provavelmente possuem uma aceitação da "convivência" 
pacífica com o animal em estudo, o que contribui para a conservação do mesmo.

ORR (1994) considera a importância de resgatar as experiências na infância o despertar para o sentido do lugar, a necessária educação para a biofilia e o pacto com a natureza. O sentimento de biofilia é extremamente útil à humanidade e contribui de forma decisiva para sua sobrevivência porque conduz à ideia de preservação dos ambientes e das espécies (FILGUEIRAS, 2007). Filgueiras (2007) também destaca que no extremo oposto ao sentimento de biofilia situa-se a biofobia, que, em sua forma mais radical e em diferentes matizes, consiste na hostilização da vida de maneira frontal ou disfarçada. Enquanto a biofilia conduz à tolerância, à convivência pacífica e enriquecedora, a biofobia é intolerante, preconceituosa, exclusivista.

Como exemplo de biofobia é possível citar neste trabalho as Figuras 2B, 2C, 3A, 3B, 3C e 3E, que revelam atitudes agressivas do homem para com o jacaré e vice-versa, denotando sentimentos de repulsa, medo, pavor (fobia). Assim, projetos conservacionistas podem ser prejudicados pela não aceitação do animal em convívio pacífico, o que exige maior atenção de pais, educadores e outros que possam influenciar no processo de aprendizagem e mudanças de atitudes a partir da percepção desses alunos.

\section{Elementos expressivos da paisagem (landmarks) nos mapas mentais}

Nos desenhos selecionados das Figuras 1 (todos) e 3A, 3B, 3E, 3F, 3G pode-se observar a presença de landmarks associados à paisagem na qual se insere o jacaré. Observa-se a representação de uma paisagem típica do Delta do Parnaíba, composta por árvores diversas (mangue, coqueiros etc.) associadas ao Manguezal (Fig. 1A, 1C, 1D, $1 \mathrm{~F}, 1 \mathrm{G}$ e 3B, 3E, 3F, 3G) ou à restinga (Fig. 1B, 1E e 3A), dois habitats ocupados pelos jacarés na região. A representação desses landmarks deve-se principalmente à presença de caminhos por terra (trilhas de acesso), água (rios e igarapés) e moradias da maior parte da população do município nas proximidades desses habitats, tornando-se uma paisagem visualizada diariamente. 
Esses marcos da paisagem demonstram que a percepção dos alunos acerca do jacaré no Delta do Parnaíba é capaz de situá-los em seus habitats reais, demonstrando uma "aproximação" com a realidade. Bezerra, Feliciano e Alves (2008), ao estudarem a percepção ambiental de alunos numa unidade de conservação na região metropolitana de Recife, PE, constataram que vários foram os desenhos em que as crianças representaram espécies arbóreas da localidade e relacionaram esse fato à faixa etária utilizada na amostra (entre nove e quinze anos), pois, de acordo com Di Leo (1985), nessa fase da infância e adolescência as crianças têm uma tendência muito forte para desenhar árvores.

Nesse contexto cabe ressaltar que o município de Ilha Grande é uma formação encravada em manguezais razoavelmente preservados, mas que não se constitui em área isenta da atividade antrópica, o que pode ser confirmado in situ (ILHA GRANDE, 2008). Com base no exposto, pode-se considerar a representação de elementos arbóreos nesta pesquisa como senso comum dos alunos da região.

\section{Considerações Finais}

A análise dos mapas mentais demonstrou atitudes ambíguas da relação do ser humano (alunos) com o jacaré, podendo variar de atitude mais positiva (conservacionista) a uma atitude negativa (destrutiva). Assim, sentimentos positivos de biofilia podem contribuir para medidas de conservação da população de jacarés da região, mas para isso tais sentimentos precisam ser cultivados, incentivados e, principalmente, praticados, pelo fato de que sentimentos negativos de biofobia podem alimentar conceitos errados e prejudiciais nas relações de convivência harmônica entre alunos e jacarés. Com base no exposto e visando trabalhar a percepção conservacionista dos alunos em favor das relações biofílicas com os jacarés e outros animais da região, sugerem-se programas de educação ambiental nas escolas. Esses programas devem abarcar desde atividades lúdicas em grupo, como brincadeiras, representações teatrais e jogos educativos, até turismo pedagógico (excursões didáticas de campo), passando pelo entorno das escolas, uma vez que a localização geográfica da escola parece influenciar a percepção dos alunos, além de áreas do município com 
lagoas e outros ambientes frequentados pelos jacarés. Acredita-se que através da sensibilização no local (babitat do jacaré), ou seja, mais próxima da realidade, é possível trabalhar de forma mais verídica os conceitos relacionados à temática conservacionista direcionada ao jacaré e obter melhores resultados através dos estímulos ambientais, uma vez que os alunos ilustraram landmarks nos quais foi possível reconhecer habitats reais ocupados pelos jacarés na região. Com a sensibilização, pode-se provocar o estímulo ao questionamento sobre a conservação da espécie e seus habitats tendo-se como ponto de partida uma única espécie-alvo, neste caso o jacaré, para então se fazer uma extrapolação para outros animais, objetivando mudanças de atitudes/comportamentos biofóbicos.

\section{Agradecimentos}

Somos gratos a todos os alunos que participaram deste trabalho, bem como aos diretores e professores das escolas estudadas, que muito bem nos receberam. Agradecemos a Thiago S. Nascimento, Werlanne M. Santanna, Werlayne M. Santanna e Francinalda R. Rocha pela ajuda na aplicação dos mapas mentais nas escolas; a João Manoel A. LeiteJúnior pela revisão do texto; ao PRODEMA-UFPI; ao DAAD (Serviço Alemão de Intercâmbio Acadêmico) pela bolsa de mestrado concedida e ao Comitê de Ética em Pesquisa da UFPI pela aprovação do projeto CAAE 0196.0.045.000-08.

\section{Referências}

ALLEN, Gary L.; KIRASIC, Kathleen C.; SIEGEL, Alexander W.; HERMAN, James F. Developmental issues in cognitive mapping: the selection and utilization of environmental landmarks. Child Development, v. 50, p. 1062-1070, 1979.

AZEVEDO, Jair Camilo.Negromonte. Crocodilianos. Biologia, Manejo e Conservação. João Pessoa: Arpoador, 2003. 122 p. 
BARROS, Luiz Ferri de. A ilha Monte de Trigo: impressões de viagens. In: DIEGUES, Antonio Carlos (Org.). Ilhas e Sociedades Insulares. Núcleo de Apoio à Pesquisa sobre Populações Humanas e Áreas Úmidas Brasileiras, USP, p. 137-153. 1997.

BEZERRA, Tatiana Marcela de Oliveira; FELICIANO, Ana Lícia Patriota; ALVES, Ângelo Giuseppe Chaves. Percepção ambiental de alunos e professores do entorno da Estação Ecológica de Caetés - Região Metropolitana de Recife. Biotemas, v. 21, n. 1, p. 147-160, 2008.

BORGES-NOJOSA, Diva Maria; CASCON, Paulo. Herpetofauna da Área Reserva da Serra das Almas, Ceará. In: ARAÚJO, Francisca Soares de; RODAL, Maria Jesus Nogueira;BARBOSA, Maria Regina de Vasconcellos. Análise das Variações da Biodiversidade do Bioma Caatinga. Brasília: Ministério do Meio Ambiente, 2005. p. 245-260.

CAMPOS, Zilca; MAGNUSSON, William; SANAIOTTI, Tania; COUTINHO, Marcos. Reproductive trade-offs in Caiman crocodilus crocodilus and Caiman crocodilus yacare: implications for size-related management quotas. Herpetological Journal, v. 18, p. 91-96. 2008.

DEL RIO, Vicente; OLIVEIRA, Lívia de (Org.). Percepção Ambiental: a experiência brasileira. São Paulo: EdUFSCar; Studio Nobel, 1997.

DI LEO, Joseph H. A interpretação do desenho infantil. Porto Alegre: Artes Médicas, 1985. 218p.

FILGUEIRAS, Tarciso S. Biofilia versus Biofobia. 2007. Disponível em: $<$ http://www.mphp.org/ciencia-e-tecnologia/biofilia-versus-biofobia.html>. Acesso em 29 abr. 2010.

FUNDAÇÃO CENTRO DE PESQUISAS ECONÔMICAS E SOCIAIS DO PIAUÍ (CEPRO). Macrozoneamento Costeiro do Estado do Piauí: Relatório Geoambiental e Socioeconômico. Teresina: Ministério do Meio Ambiente, 1996. $221 \mathrm{p}$.

ILHA GRANDE. Prefeitura Municipal. Plano Diretor Participativo de Ilha Grande, Piauí. Relatório Final. Diagnóstico e Prognóstico. Ilha Grande: 2008. (v. 1). 
INSTITUTO BRASILEIRO DE GEOGRAFIA E ESTATÍSTICA (IBGE). IBGE Cidades. 2007. Disponível em: < http://www.ibge.gov.br>. Acesso em 10 jul. 2008.

INTERNATIONAL UNION FOR CONSERVATION OF NATURE (IUCN). Red List of Threatened Species. Version 2010.2. Disponível em: <www.iucnredlist.org>. Cited: Aug. 022010.

KOZEL, Salete. Das imagens às linguagens do geográfico: Curitiba, a Capital Ecológica. 2001. 310 p. Tese (Doutorado em Geografia) - Faculdade de Filosofia, Letras e Ciências Humanas, Universidade de São Paulo, São Paulo, 2001.

LOEBMANN, Daniel; HADDAD, Célio Fernando Baptista. Amphibians and reptiles from a highly diverse area of the Caatinga domain: composition and conservation implications. Biota Neotrop., v. 10, n. 3, p. 227-256, 2010.

MACHADO, Lucy Marion Calderini Philadelpho. A percepção do meio ambiente como suporte para a educação ambiental. In: POMPËO, Marcelo Luiz Martins (Ed.). Perspectivas da Limnologia no Brasil. São Luís, MA: União, 1999. cap. 4.

MANSANO, Cleres do Nascimento; OBARA, Ana Tiyomi.; KIOURANIS, Neide Maria; PEZZATO, João Pedro. A escola e o bairro: percepção ambiental e representação da paisagem por alunos de uma $7^{\mathrm{a}}$ série do ensino fundamental. In: ENCONTRO NACIONAL DE PESQUISA EM EDUCAÇÃO EM CIÊNCIAS, 5., 2005. Bauru-SP. Anais... Bauru: UNESP, 2005.

MAROTI, Paulo Sérgio. Educação e percepção ambiental das comunidades do entorno de uma Unidade de Conservação. 2002. 218 p. Tese (Doutorado em Ciências) - Programa de Pós-Graduação em Ecologia e Recursos Naturais, Universidade Federal de São Carlos, São Carlos, 2002.

MELOS, Marcia Rejane Riccioni de. A busca da percepção da relação homem/natureza dos alunos do Colégio Militar de Campo Grande, por meio de ações desenvolvidas num projeto interdisciplinar. 2005. Dissertação (Mestrado em Educação) - Programa de Pós-Graduação em Educação, Universidade Federal de Mato Grosso do Sul, Campo Grande, 2005. 
NEIMAN, Zysman. A Educação Ambiental através do contato dirigido com a natureza. 2007. Tese (Doutorado em Psicologia) - Instituto de Psicologia, Universidade de São Paulo, São Paulo, 2007.

NIEMEYER, Ana Maria de. Desenhos e mapas na orientação espacial: pesquisa de ensino de antropologia. Textos Didáticos, Campinas, n. 12, p. 1-24, jan. 1994.

ORR, David. Earth in Mind on Education, Environment and the Human Prospect. New York: Island Press, 1994.

RODRIGUES, Miguel T. Conservação dos répteis brasileiros: os desafios para um país megadiverso. Revista Megadiversidade, v. 1, n. 1, p. 87-94, 2005.

RUEDA-ALMONACID, José Vicente; CARR, John L.; MITTERMEIER, Russell A.; RODRÍGUEZ-MACHECHA, José Vicente; MAST, Roderic B; VOGT, Richard C.; RHODIN, Anders G. J.; OSSA-VELÁSQUEZ, Jaime de la; RUEDA, José Nicolás; MITTERMEIER, Cristina Goettsch. Las tortugas y los cocodrilianos de los países andinos del trópico. Conservación Internacional. Bogotá: Editorial Panamericana, Formas e Impresos, 2007. 538 p. (Serie de guías tropicales de campo, n. 6).

SALERA JÚNIOR, Giovanni. As Crianças e os Jacarés. Publicado no site O Melhor da Web em 08 dez. 2008. Código do Texto: 7146. 2008. Disponível em: <http://www.poesias. omelhordaweb.com.br/comentario_poesia.php> Acesso em: 01 ago. 2009.

SILVA, Thiala Fernandes da Paz; COSTA NETO, Eraldo Medeiros. Percepção de insetos por moradores da comunidade Olhos D’água, município de Cabaceiras do Paraguaçu, Bahia, Brasil. Boln. S.E.A., n. 135, p. 261-268, 2004.

UNITED NATIONS ENVIRONMENT PROGRAMME - WORLD CONSERVATION MONITORING CENTRE (UNEP-WCMC). CITESlisted species database: 2010. Disponível em: <www.cites.org/eng/resources/species.html>. Acesso em: 01 ago. 20010.

VILLAÇA, André Martins. Uso de habitat por Caiman crocodilus $e$ Paleosuchus palpebrosus no reservatório da UHE de Lajeado, Tocantins. 2004. 59 p. Dissertação (Mestrado em Ecologia de Agroecossistemas) - Programa de Pós-Graduação em Ecologia de Agroecossistemas, Escola Superior de Agricultura Luiz de Queiroz, Universidade de São Paulo, Piracicaba, 2004. 
Artigo: recebido em 04/07/2010 - aprovado em 17/12/2010 